\title{
VIRA, VIROU A MICARETA \\ EMPLACOU!
}

\author{
Clarissa Valadares Xavier* \\ clarissa.valadares@gmail.com \\ Carlos Eduardo Santos Maia** \\ carimaia@uol.com.br
}

Resumo: Este artigo pretende explorar a história das festas consideradas "fora de época", as quais eram forma de ruptura no calendário litúrgico, como serração da velha (Portugal) e a Micarème (França). No Brasil, a cidade de Salvador foi o palco das transformações no modo de fazer a festa. As modificações e interferências diretas da capital soteropolitana alteraram a sua configuração e esta começou a ser "exportada", havendo, atualmente, um circuito micaretesco que se estende por todo ano. Assim, as micaretas conquistaram lugares próprios, ultrapassaram o propósito temporal inicial e redefiniram o modelo de festa, estando a nova roupagem atrelada aos trios elétricos do carnaval de Salvador.

Palavras-Chave: Micareta, Carnaval fora de época, Salvador.

\section{INTRODUÇÃO}

As micaretas que, de certa forma, uniram-se aos trios elétricos originários do carnaval, especificamente na cidade de Salvador, constituem-se em nosso objeto de estudo. Esta festividade virou e revirou sua real pretensão, tornando-se "febre" no Brasil e emplacando em lugares diversos. O objetivo é problematizar as micaretas a partir de seu caráter espaço-temporal, já que atualmente ocorrem várias festas com esta nomenclatura, porém nem sempre

* Doutoranda no Instituto de Estudos Sócio-Ambientais da Universidade Federal de Goiás (UFG). Bolsista da Coordenação de Aperfeiçoamento de Pessoal de Nivel Superior (CAPES).

** Doutor em Geografia pela Universidade Federal do Rio de Janeiro. Professor Adjunto no IESA da UFG. 
relacionadas com o carnaval "de rua fora de época", como originariamente a festividade da micareta sugeria.

Em efeito, o que é discutido e apresentado neste artigo permeia a inserção dessa festa no Brasil, como também de outras festas consideradas "fora de época" que, inicialmente, representavam uma ruptura no calendário litúrgico, realizadas no período da quaresma, como a serração da velha, oriunda de Portugal, e a Micarème, proveniente da França. Posteriormente é retratado como, a partir desta última, surgiu a micareta no Brasil na qualidade de uma festa com lugares próprios e que definiu um certo modelo de festividade, no qual se nota a forte e fundamental interferência do carnaval de Salvador.

Por meio da análise deste modelo de folia exportado, verifica-se que a micareta tem se disseminado em todo o país, e até mesmo além de nossas fronteiras, estando diretamente relacionada com o turismo nas cidades que a promovem e implicando na existência de um calendário de micaretas, que ultrapassa a temporalidade inicialmente proposta (período da quaresma). Paralelamente, padrões foram instituídos, locais foram criados e lugares ressignificados.

\section{As Manifestações Carnavalescas Fora de Época: Jejuar é PReCiso?}

Tradicionalmente, o carnaval é festejado de domingo à terça-feira anterior aos quarenta dias que se inicia nas cinzas e se estende até domingo de Páscoa, como prevê o calendário litúrgico. Destacar estas datas é importante não só para compreender a realização de festas consideradas “fora de época”, mas também para permitir melhor esclarecimento quanto à sua estruturação e seus propósitos iniciais e atuais. Vale lembrar que, em algumas datas reservadas, a Igreja Católica permitia a realização de grandes festas coletivas. Segundo Araújo (2000), estas datas serviam para que os homens - temporariamente livres da labuta e obrigações diárias - pudessem louvar os santos, exteriorizar publicamente a fé e entregar-se ao descanso e às diversões, após haverem honrado os compromissos religiosos.

Essas datas podiam ser fixas, como é o caso da celebração de um santo, na qual se definia, por exemplo, a referência ao dia de sua morte, ou regulamentadas por outros critérios, como a lunação, tornando-se móveis. Porém, as festas objetivavam, em última instância, manifestar a devoção do homem a Deus (principalmente Filho e Espírito Santo) e aos santos, mediante o culto externo, se apropriando, às vezes, das datas de antigos ritos pagãos relacionados às atividades agrícolas ou aos solstícios e equinócios, que eram ressignificados dentro dos cânones estabelecidos pela Igreja - prática que 
o próprio papa Libério, que teve o seu papado de 17 de maio de 352 até 24 de setembro de 366, adotou para oficializar 25 de dezembro como sendo o Natal a fim de cristianizar as homenagens ao Deus Mitra.

O carnaval é um exemplo de festa com data móvel, variando do início de fevereiro à primeira quinzena de março, segundo o dia da Páscoa. De acordo com Braga (1985), fixou-se a data de Páscoa para ser celebrada anualmente no primeiro domingo depois da lua cheia que se seguia ao equinócio da primavera no hemisfério norte. Os três dias de carnaval antecipavam os penosos dias de jejum da quaresma que, assim como o Natal, foi institucionalizada no século IV, mas ganhou tons mais severos no episcopado de Gregório I, no século VII, e teve sua data oficializada no século XI por Urbano II (FERREIRA, 2004). Indubitavelmente, isto contribuiu para que o carnaval mantivesse o seu caráter de festa dos excessos com manifestações de orgia e fartura, num tempo em que "se pode tudo"; pois, para os fiéis, após este período, chegava a hora das penitências e dos sacrifícios, dos jejuns e da sobriedade. "Desse modo, o Carnaval seria um período introdutório, um intróito, ou ainda, um entrudo reservado ao gozo máximo daquilo que não poderia ser consumido e praticado durante o período da quaresma" (SILVA, 2009), principalmente na transição da Idade Média à Moderna.

Araújo (2000) adverte que o dogma da Igreja que prescrevia a abstinência na Quaresma, a começar na Quarta-feira de Cinzas, era tão arraigado que se considerava a sua não observação heresia, podendo ser levado o infrator aos tribunais da inquisição. Contudo, exatamente na metade do período da Quaresma, na passagem de quarta-feira para a quinta-feira da terceira semana, havia uma quebra no quadro de contrição, tristeza e jejum por meio de uma festividade. Observe-se, assim como Bakhtin (1987), que não se pode atribuir às festividades um caráter apenas de descanso:

As festividades (qualquer que seja o seu tipo) são uma forma primordial, marcante, da civilização humana. Não é preciso considerá-las nem explicá-las como um produto das condições e finalidades práticas do trabalho coletivo nem, interpretação mais vulgar ainda, da necessidade biológica (fisiológica) de descanso periódico. As festividades tiveram sempre um conteúdo essencial, um sentido profundo, exprimiram sempre uma concepção do mundo (BAKHTIN, 1987, p. 7-8).

Desse modo, a quebra do jejum era parte da vida do povo e expressava uma concepção de mundo gestada em determinada cultura (judaico-cristã). Em sendo parte integrante da cultura, esta (a quebra do jejum) compreendia 
modos de vida, ritos e costumes, como Thompson (1998, p. 22) observa ao definir este conceito:

[...] não podemos esquecer que 'cultura' é um termo emaranhado, que, ao reunir tantas atividades e atributos em um só feixe, pode na verdade confundir ou ocultar distinções que precisam ser feitas. Será necessário desfazer o feixe e examinar com mais cuidado os seus componentes: ritos, modos simbólicos, os atributos culturais da hegemonia, a transmissão do costume de geração para geração e o desenvolvimento do costume sob formas historicamente específicas das relações sociais e de trabalho.

Pode-se dizer ainda que a quebra do jejum, como festa, apresentava aquele aspecto assinalado por DaMatta (2001, p. 40) de se constituir em momento especial de convivência social em que certos aspectos da realidade são postos em destaque (no caso, a futura abstinência) e que, diferentemente de outros eventos, possui momentos extraordinários marcados pela alegria e por valores que são considerados altamente positivos, no caso, as orgias e patuscadas. A quebra do jejum demonstraria ainda a inserção dos mesmos sujeitos, objetos e estrutura de relações da vida social transfigurados, com a troca em excesso de bens, serviços e significados. A festa exagerava o real, tomando posse da rotina da quaresma sem rompê-la; mas excedendo sua lógica, forçando as pessoas ao "breve ofício ritual da transgressão" (BRANDÃO, 1989).

A quebra do jejum ao meio, na França, recebeu o nome de MiCarème, como a etimologia da palavra evidencia, cujas evidências como solenidade datam de meados do século XVII nos escritos de Jean Loret, mas que ganha tônica de festividade feminina a partir do século XVIII. Paulatinamente, a presença feminina ganha maior relevo nos desfiles de carros alegóricos em que se destacava a presença de uma rainha, neste caso de Paris ou de Nice, que era eleita entre as moças da classe operária do lugar. A Enciclopédia Delta-Larousse (1992) ratifica tal origem, ao definir que Micarème vem do termo francês Micarème, derivado de Demi-carème, que indica uma festa que acontecia no meio da quaresma, com a presença de estudantes e trabalhadores, em que era eleita a rainha das lavadeiras, acontecendo a partir da Comuna de Paris. Cardoso (2000) confirma ainda tal definição, ao relatar que Mi-carème exprime o meio da quaresma, a terceira quinta-feira, ou o vigésimo dia da quaresma que era uma ocasião que incluía desfile de carros ornamentados com música, comida e boa diversão. Posteriormente, se analisará a estrutura e funcionamento desta festividade no Brasil. 
Outra manifestação que servia como pausa da quaresma ocorria em Portugal: a Serração da Velha. Esta festividade europeia se diferenciava um pouco dos cortejos carnavalescos, pois seu ritual consistia em serrar a figura de uma velha, feita ordinariamente de pano e recheada de palha, que personificava a Quaresma. Em muitas ocasiões serrava-se a velha defronte a casa em que residia algum (a) anciã (o), geralmente antipatizado na comunidade, antecipando assim, simbolicamente, a sua morte. Vainsencher (2008) detalha que os jovens realizavam desfiles nas ruas usando máscaras e fantasias, coletavam dinheiro e doces, declamavam poesias, cantavam e dançavam, ao som do triquelitraque - um instrumento constituído por uma tábua e várias fileiras de martelinhos que nela batiam, produzindo um barulho suigeneris e de latas arrastadas. Também era realizada a leitura do testamento da velha com a exposição dos beneficiários na partilha dos bens. A seguir, um jovem do sexo masculino, com o instrumento de suplício (no caso, o serrote), fazia gestos que representavam a "serração da velha", enquanto todos cantavam e repetiam o refrão: "Serre-se a velha! Força no serrote! Serre-se a velha! Força no serrote!” Vainsencher (2008).

De acordo com a mesma autora, a Serração da Velha representava uma válvula de escape da juventude frente a determinados pontos e visava: 1) relaxar o controle dos cardápios nos dias santos, que exigiam os tradicionais jejuns e penitências (o folguedo rompia com a austeridade da Semana Santa e com o código de restrição alimentar e o jejum conventual, peculiar à Quaresma, em memória ao sofrimento de Jesus Cristo); 2) reivindicar maior liberdade nos namoros as moças eram muito reprimidas, sendo subjugadas por mães, avós, tias e madrinhas, tidas como guardiãs da honra e dos bons costumes; 3 ) incentivar o surgimento de um modelo feminino mais libertário, que possuísse mais direitos; e 4) aliviar as tensões sociais existentes entre as gerações. Del Priore (2001, p. 296) complementa exarando que os jovens em "batalha simbólica contra a morte [...] celebravam o fim do inverno (em fevereiro, no hemisfério norte), o final da Quaresma e o aniquilamento da esterilidade, homenageando a chegada do verão e da fecundidade".

No Brasil, Cascudo (1979) relata que esta manifestação européia, ultrapassou fronteiras, no final do século XIX, e chegou a ocorrer no Nordeste. Algumas vezes, fizeram-na fora desse período de quaresma, com intenções políticas, havendo, paralelamente, expressões de desagrado em relação à folia, o que gerou um documento (Código de Posturas de Papari, atual Nísia da Floresta, no Rio Grande do Norte, em 1887) proibitivo à sua realização.

Também foi identificada a ocorrência desta festividade nos séculos XVIII e XIX no litoral sul do Rio de Janeiro. Em Goiás, Pohl (1976, p. 144- 
5) descreveu uma Serração da Velha no alvorecer do século XIX, sobre a qual comenta:

Deve-se ainda mencionar uma farsa denominada Serração da Velha, indicadora de que já passou a metade da quaresma. Essa farsa é organizada pelos soldados. Para a zombaria é escolhida, entre as moradoras da cidade, uma mulher já idosa, mas ainda coquete. Quando pois, é chegada a idade, já essas mulheres ficam preocupadas e receosas de serem vítimas. Faz-se uma figura recheada de palha, tão parecida quanto possível com a mulher em questão, com trajes iguais ao que ela costuma usar, de modo a ser reconhecida imediatamente. Numa das mãos põem-lhe um rosário e na outra, uma serra para indicar que o jejum quaresmal é cortado ao meio [...] Um grotesco mascarado abre o cortejo e, durante as paradas, lê o testamento da velha, composto com grande exagero, em que são ridicularizadas suas vaidades de maneira acintosa.

Nota-se, nesta citação, que o ritual de Serração da Velha tinha algo de semelhante ao charivari, manifestação extremamente popular na Europa pré-industrial; constituindo-se numa espécie de julgamento público, de difamação daquele que houvesse desagradado ou transgredido os preceitos e valores morais da comunidade (ARAÚJO, 2000). De acordo com Del Priore (2001, p. 282), “a 'Serração da Velha” deve ter sido tão freqüente no mundo rural brasileiro, que um dos personagens de José Lins do Rego em Fogo Morto, Marta, bizarra solteirona, aguarda com horror o som terrível e acusatório do panelaço sob sua janela!”.

Duarte (2005) informa que a Serração da velha, em Portugal, ocorria na mesma data da Mi-carème francesa, ocupando o meio da quaresma, na quinta-feira da terceira semana, sendo que a Mi-carème tem seu caráter popular vinculado aos operários e às lavadeiras, que elegiam suas rainhas, distribuíam brindes e a eles associaram-se os estudantes, durante a Comuna de Paris.

\section{O Tempero Baiano}

A Micarème apresentava também um ritual muito curioso, em que o julgamento não era do público, mas havia um mistério a ser desvendado; pois as pessoas se disfarçavam e seus familiares e vizinhos deveriam identificá-las sob máscaras e fantasias que, ao lado da alteração da voz, tornavam o jogo mais difícil. Para as crianças, a Micarème significava uma recompensa àquelas bem-comportadas, pois recebiam doces e bombons dentro de suas meias de lã dependuradas atrás das portas ou nas cabeceiras de suas camas; enquanto, 
para as desobedientes, a Micarème estava relacionada com uma personagem que os pais usavam para amedrontá-las e fazê-las se comportarem. A festa para este público infantil tinha o nome de Petit Mi-carème.

No Brasil, a Micarème recebeu ares novos, pois, na verdade, a festividade se instalou para, posteriormente, ser-lhe atribuído o nome de Micarème. A Micarème surgiu como uma força capaz de promover a melhora nas festividades carnavalescas, que vinham perdendo concorrência popular. Há registros de que a Micarème aconteceu em várias partes do país, como por exemplo, a citação, em 1908, de uma revista ilustrada denominada "FonFon", na qual se propunha a realização de festas de mi-careme dedicadas aos operários no Rio de Janeiro (MORAES, 1958). Porém, a festa só sobreviveu e perdurou na Bahia, onde destacamos a cidade de Salvador.

A micarème é uma festa recente em Salvador, tendo surgido na segunda década do Século XX, por volta de 1914. Em 1927 esta festa já era reproduzida em outras cidades do Estado da Bahia, como em Vitória da Conquista, demonstrando a sua força de adesão. Quanto aos aspectos profanos e religiosos, estes eram bem diferentes do que ocorria na Europa. No princípio, o seu caráter profano se dava através de desfile de clubes e o caráter religioso, mediante a festa da ressurreição de Cristo, ou mesmo com uma dimensão humanitária manifesta em distribuição de carne aos pobres (DUARTE, 2005; VIANNA, 1986), o que às vezes terminava em tumulto.

O lado sagrado da festa é retratado pelo antropólogo Rego (1968), para quem a Micarème integrava o quadro do calendário eclesiástico, que se iniciava com o Natal, seguindo-se a Epifania (o dia dos Santos Reis), a Lavagem do Bonfim, o Carnaval e culminando com a Micarème. $\mathrm{O}$ autor relata que, especificamente em Salvador, no sábado de Aleluia, às 10 horas da manhã, iniciavam-se os festejos e, no Domingo de Páscoa, o público ficava na rua até meia-noite. Duarte (2005) comenta que a influência religiosa restringiu-se ao período de sua realização e à observação de certos horários para início e término da festa. Mas vale ressaltar que até mesmo a data se modificará posteriormente. Desse modo, o lado mais significativo dessa festividade era o profano, o que se relacionava com a economia, pois se procurava retomar a folia carnavalesca após o período de abstenção da quaresma. Sobre este ponto Duarte $(2005$, p. 7$)$ se expressa:

A Micarème profana foi aquela inventada para nutrir de força e energia um carnaval que perdia tônus a cada ano, na segunda década do século XX, informa Antônio Vianna, seu original comentarista. A Micarème acontece pela primeira vez em terras baianas no ano de 1914, refazendo o mesmo circuito 
da festa momesca. Realizar a Micarème foi uma iniciativa dos diretores do bloco 'Fantoches da Euterpe', que organizaram um préstito carnavalesco para sair no domingo de Páscoa, 'sem ofensas à Igreja, obtendo a adesão dos outros grandes clubes, 'Cruz Vermelha e 'Inocentes em Progresso'.

Rego também ressalta o lado profano da festa, uma vez que Micarème e Carnaval ocorriam em épocas diferentes, "esta última viria como reforço do carnaval, pois mesmo ocorrendo num único dia e sendo mais fraca que o carnaval, criava dois pólos de folia: se desaparecesse um, ficava o outro" (REGO, 1994 apud DUARTE, 2005, p. 9). O aspecto econômico, por sua vez, é observado por Hildegardes Vianna, em artigo publicado no Jornal A Tarde de 05 de abril de 1959, no qual noticia que a Micarème foi negócio bem planejado, bem discutido e posto em execução por mãos de mestres, notando-se uma tentativa bem sucedida de salvar de morte certa o carnaval, que perdia público de ano para ano e, salvo o carnaval, estaria também salvo o comércio.

Assim, a festividade brasileira surgiu e depois, influenciada pela francesa, recebeu este nome; porém desde o início, a Micarème em Salvador ocorria não no meio da quaresma, como o termo francês indica, mas sim no fim do período de sacrifícios com os objetivos de reavivar os ânimos e reativar a competição entre entidades carnavalesca (trazendo de volta os carnavais memoráveis) e impulsionar o comércio (VIANNA, 1986). Desta forma, a Micarème naquela cidade era a festa ou baile que se realizava na Páscoa para festejar a Aleluia, na Semana Santa. Para Rego (1986), por isso, a Micarème nesse feitio é uma invenção baiana, não tendo partido de uma iniciativa popular, pois os comerciantes do Comércio e da Baixa dos Sapateiros eram os grandes incentivadores, podendo assim ser considerada pelo mesmo autor como um carnaval em miniatura, já que a relação entre comércio e folia era próxima àquela que ocorria na cidade na época carnavalesca.

Em Salvador, a festa, como dissemos, ganhou tons carnavalescos com desfiles nas ruas de três grandes clubes, cordões, blocos, corso, desfile de foliões fantasiados em carros abertos, além de batalhas de confete e serpentina. Vianna (1983) observa que ainda havia línguas de sogras, mamães-sacodes, limpa-chãos e nariguetas; mas tudo modificou-se, com a marchinha e a sombrinha incorporadas aos poucos. A motivação de sua realização se estendeu por outras áreas do Estado da Bahia, como relata o periódico de Vitória da Conquista: "A Ribalta", órgão oficial do Grêmio Dramático Castro Alves, em sua sexta edição: 
Quem não ficou com saudade dos ruidosos dias carnavalescas? Ninguém. E como esquecer a saudade das alegrias extinctas? --- Façamos a Mi-careme... E a boa idéia, partida da família do Sr. Demosthenes Rocha, achou acolhida, se impoz, se tornou-se a realidade que nossa urbs encheu da mais vibrante alegria. $\mathrm{E}$ a cidade, naqueles dias, se encheu duma vida nova, aplaudindo os diversos cordões que se apresentavam distribuindo a alegria e o riso esfusiante (Jornal A Ribalta, 1927).

A Micarème, já no Brasil e especificamente nas terras baianas, foi combatida pela Igreja por considerar imprópria a sua data de realização. Para a instituição religiosa era absurdo ter um carnaval na Páscoa. Os conflitos acentuaram-se quando, em 1930, a Micarème foi transferida, por causa do mau tempo, para a Pascoela, no domingo seguinte à Páscoa. Nesta data haveria a procissão de São Benedito, que não aconteceu por causa do furdunço. Assim a perseguição da Igreja Católica fez com que a Micarème enfraquecesse perante o público na década de 30 (DUARTE, 2005). Com vistas a realimentá-la, nos primeiros anos desta década, foi promovida a escolha de um novo nome para a festa, já que havia se transferido definitivamente para a Pascoela. Essa estratégia de renomeação confirmou o aspecto de festa planejada e com interesses comerciais que justificavam o resgate e a permanência. Algumas denominações foram selecionadas previamente por historiadores, jornalistas e demais profissionais diretamente envolvidos com a realização da festa, sendo personagens de renome da sociedade baiana, mas a escolha final foi por voto popular entre as seguintes: Refolia, Micareta, Carnavalito, Arlequinada, $1^{\circ}$ Festa Outonal, Mascarada, Bicarnaval, Precarême, Brincadeira e Remate. Nas finais ficaram Refolia e Micareta (VIANNA, 1983). Em 05 de abril de 1935 os jornais traziam o resultado: vencera Micareta por 3 votos.

Duarte (2005) afirma que o vocábulo Micareta é uma invenção brasileira, baiana propriamente, assim como a festa que leva seu nome. Cita que este nome foi encontrado no livro de Nicéas (1991), 'Verbetes para um dicionário do carnaval brasileiro', como "gíria baiana para designar o segundo carnaval da cidade de Feira de Santana, Bahia, festejando a Aleluia com o término da Semana Santa", no qual também há o verbete "Mi-carême - Vocábulo francês com o significado de meia-quaresma". A referência do nome micareta está relacionada com o carnaval da cidade de Feira de Santana, apesar da escolha do novo nome desta festa ter ocorrido na capital baiana e sua realização iniciada nesta cidade (Salvador). Porém, a ligação do nome com a cidade de Feira de Santana há por esta ser considerada como a pri- 
meira a realizar "carnaval fora de época" no Brasil, apesar desta afirmação ser questionável.

\section{Salvador et Orbi}

Revigorada com modificação do nome, a festa se manteve no cenário de Salvador e começou a ser "exportada". De uma invenção dos comerciantes, recebeu o gosto popular e se instalou em outras cidades, de modo que, em 1937, segundo alguns autores, como Duarte (2005) e Santos (2001), houve a primeira micareta fora desta cidade, mais especificamente em Feira de Santana, na Bahia, uma cidade a $100 \mathrm{~km}$ da capital, conforme se mencionou. Silva (1986), entretanto, afirma que a data da primeira Micareta foi em 1933, na cidade de Jacobina, Bahia, baseado em registros do jornal jacobinense "O Lidador". Já Lemos (1995) defende que a micareta parece ter se originado em Jacobina, em 1912, por iniciativa de Porcino Maffei, ali residente, organizando o bloco "As Copas". Na edição de 7 de abril de 1935, este mesmo periódico publicava as novidades da capital referentes à mudança de nome da festa e evocava todos a participar do evento:

Despertai, foliões, para o delírio que impolga. Erguei-vos, jacobinenses, em êxtase de alegria e vinde com as 'Sertanejas Alegres' festejar o 'Bicarnaval', 'Micareta,' 'Refolia', ou 'Mi-careme' que a 28 do corrente reinará sob louco enthusiasmo, espancando tristezas e dissidências. A cousa vai ser da outra vida e não haverá quem resista a tentação (Jornal $O$ Libador, 1935).

Nota-se, então, que há impasses quanto ao mérito de qual cidade sediou a primeira micareta fora de Salvador, mantendo o formato inspirado na festividade que ocorria na capital. Parte das referências consultadas relaciona-se apenas à Micareta de Feira de Santana, talvez por sua maior proximidade com a capital e pela sua importância urbana, ou mesmo por causa da dimensão que tomou com o passar dos anos. Seguindo a mesma motivação soteropolitana, em Feira de Santana a Micareta também foi uma folia para suprir o declínio da festa carnavalesca na cidade.

Impulsionadas com o fracasso do carnaval por causas das chuvas, no ano de 1937, as festas Pós-páscoa se transformaram no verdadeiro carnaval. Todavia, a Micareta em Feira de Santana teve data e duração diferentes, pois, em Salvador, a Micarème era geralmente comemorada no Domingo de Páscoa e a Micareta fixou-se no domingo seguinte, o da Pascoela. Por outro lado, em Feira de Santana ela vai ocorrer quinze dias após a Páscoa (talvez para 
não competir com aquela realizada na capital e atrair maior público). Em termos de duração, enquanto em Salvador a festa era feita em um único dia, em Feira de Santana ela passou a durar os mesmos quatro dias do carnaval, variando em até cinco dias (ALENCAR, 1968). Os seus lugares, que compõem uma geograficidade da micareta, também não seguiram o modelo da capital, pois em Salvador a festa estendia-se tanto pelas ruas quanto pelos clubes; enquanto em Feira de Santana, por vez, a geografia da micareta fica restrita ou somente às ruas, ou somente aos clubes.

Pode-se dizer que a micareta apresentou características mais evidentes do que a Micarème como um modelo a ser seguido, pois os paradigmas do carnaval de Salvador foram intencionalmente adotados. Sugere-se ainda que a sua publicidade também se deva à construção da rodovia para Salvador, BR-324, que dá acesso entre esta cidade e Feira de Santana, na década de 30, facilitando o deslocamento das pessoas interessadas em participar deste carnaval soteropolitano e, assim, levando suas aspirações de reviver estas emoções em suas cidades no período das micaretas.

De acordo com Alencar (1968) em Feira de Santana, a micareta foi sustentada inicialmente pela Sociedade Filarmônica 25 de março, quando inúmeros fatores determinaram seu cancelamento, pelo menos nas ruas. $\mathrm{Na}$ década de 40, o Feira Tênis Clube centralizou as festas micaretescas e, na de 60, o Clube de Campo Cajueiro. Enquanto isso a festividade se espalhava pelo Recôncavo, Sul e Sertão do Estado.

Duarte (2005) ressalta que houve um "intervalo" na concorrência de público da micareta em Feira de Santana, pois esta festividade decaiu, juntamente com o carnaval, durante o período da guerra. No pós-guerra, porém, recupera-se e volta a agradar de modo que, em 1951, já apresentava em sua realização a mais recente novidade do carnaval de Salvador, os trios elétricos, como relata Osmar: "Em 51 tocamos na micareta de Feira de Santana, já com a caminhonete. Quem nos levou foi Fantoches da Euterpe. O Fantoches foi para lá desfilar e nós fomos juntos, a convite da Secretaria de Turismo. Ficamos hospedados junto com o Fantoches. Nós íamos puxando o carro do Fantoches." (OSMAR, 1994 apud DUARTE, 2005, p. 14). Assim nasceu a relação entre as micaretas e os trios elétricos, os quais atualmente não se desassociam um do outro, parecendo ser vital a consumação desta união.

Porém, Duarte (2005) atenta para a estranha configuração carnavalesca desta micareta de 1951 em Feira de Santana, porque havia o carnaval do passado, com famosos préstitos das sociedades carnavalescas, e ao mesmo tempo o carnaval do futuro, representado pelo trio elétrico. Simultaneamente, se mesclavam uma forma elitista de fazer a festa, com as grandes sociedades 
desfilando para o povo aplaudir - como uma atração de forte apelo popular - e uma torrente de povo seguindo um caminhão iluminado, que tocava no lugar da tradicional banda. Como relata Orlando Campos, a participação do trio se tornou permanente: "Faz 38 anos que toco na Micareta de Feira de Santana: de 61 para cá não perdi uma, todo ano o Tapajós participa" (CAMPOS, 1994 apud DUARTE, 2005, p. 16).

A micareta modificou-se aos poucos e assumiu cada vez mais semelhanças com o carnaval de Salvador. Atualmente, a festa micaretesca ocorre fortemente no interior da Bahia e é possível brincar "o carnaval de Salvador" em outras épocas do ano e fora dali. De acordo com Ferreira (2004), um fator que propulsionou isto foi que, em 1969, o cantor Caetano Veloso com sua música que tinha nos versos a frase "Atrás do trio elétrico só não vai quem já morreu" divulgou nacionalmente essa brincadeira e, a partir de então, até a prefeitura de Recife passou a contratar o Trio Elétrico Tapajós para animar a sua folia.

A dimensão da festa micaretesca é tamanha que, em algumas cidades, esta possui mais importância do que o carnaval propriamente dito, como ocorre em Goiânia - Goiás. Também, pode-se atribuir seu sucesso à fidelização cada vez maior ao estilo da festa, conformada nos padrões do carnaval de Salvador, como demonstra a Figura 1 na Micareta de 1974 em Conceição do Coité, na Bahia.

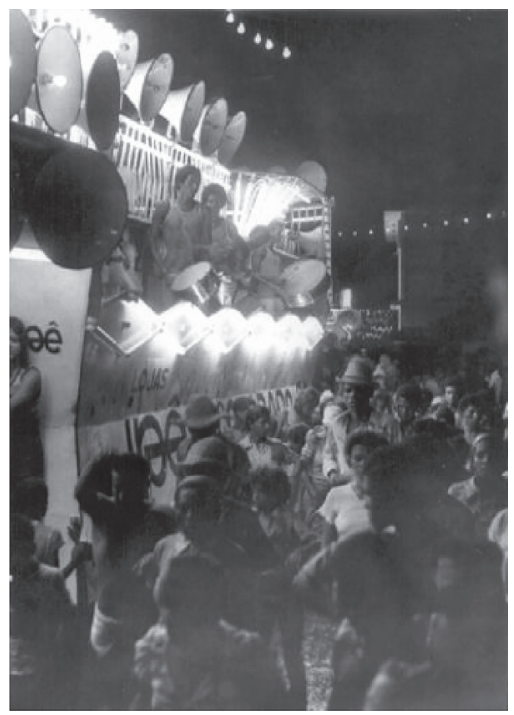

Figura 1: Micareta de Conceição do Coité - Bahia/ 1974

Fonte: Disponível em: <http://www.fotolog.com.br/prfragoso/36983960>. Acesso em: 05/04/2009

Hist.R., Goiânia, v. 15, n. 2, p. 323-340, jul./dez. 2010 
Na ilustração da Figura 1, visualiza-se já em 1974 a inserção do trio elétrico, o qual se tornou elemento indispensável para a realização dessa festividade e deu outra virada no modelo festivo de "micaretar" que emplaca atualmente.

Este modelo derrubou fronteiras, indo se aventurar em outros locais, em outros estados. Um fato que demonstra sua amplitude é exemplificado com o convite do trio elétrico Tapajós para participar do carnaval carioca em 1975. No evento, Orlando Campos entrou com seu trio na Avenida Presidente Antônio Carlos, que servia de palco para o desfile das escolas de samba, tocando "Cidade Maravilhosa" em ritmo de frevo:

Em 75 a Souza Cruz colocou no Rio dois carros: um nos bairros e outro no centro. No centro, eu abri o desfile das escolas de samba. Quando entrei na passarela tocando no trio 'Cidade Maravilhosa' em ritmo de frevo - ainda não existia cantor-, botei aquela gringada pra descer toda, ali na Antônio Carlos. No segundo dia, quando as escolas de samba viram o sucesso do trio, não deixaram a gente entrar na avenida. Era para a gente sair todos os três dias. Quando eles viram o sucesso no outro dia não deixaram. O coronel disse: 'Sai daí senão eles te matam. Não vai adiantar!'. Eu tive que sai. Fui para a Rio Branco, para outros bairros, mas não pude participar mais. Daí em diante, até hoje, não deixaram mais entrar para puxar o desfile das escolas de samba (CAMPOS, 1994 apud DUARTE, 2005, p. 58).

Na visão de Armando Luiz Sampaio Silva, em entrevista concedida para Duarte (2005), os cordões, batucadas, blocos de sujos e escolas de samba perderam espaço na micareta de Feira de Santana principalmente pela questão financeira, já que estes não possuíam recursos para cobrir seus custos. Mas também estes não despertavam mais o interesse do público, que preferia apreciar as estrelas da axé-music.

As festas criaram um conflito entre preservar aspectos da cultura regional e conciliá-la com os padrões do carnaval de Salvador, o que é almejado pelo público, lembrando que os investidores também cobram isto, pois sabem o que pesa mais nos retornos que conseguirão. Este conflito ultrapassa as características da folia e se manifesta na geografia do espaço dos cortejos, circuitos, percursos dos trios e seus respectivos blocos.

Ainda tendo Feira de Santana como exemplo, o empresário Armando Luiz Sampaio Silva (1994 apud, Duarte, 2005) salienta esta disputa pelo espaço e sua complicada gestão, pois há um espaço físico de ' $x$ ' quilômetros no qual se tem para administrar a participação dos trios, dos blocos, das escolas 
de samba, dos blocos afro, afoxés, aliada à tentativa da prefeitura de inserir a cultura local nos locais nobres da festas. Destarte, em uma das edições necessitou-se de pessoas para abrirem espaços aos desfiles das atrações regionais, mas o público demonstrou falta de interesse e foi aos poucos embora da rua, desocupando os camarotes e até mesmo os trios elétricos pararam.

Mas este modelo de carnaval conquistou e emplacou noutros tempos e lugares, de modo que no dia 21 de abril de 1989 houve a primeira micareta fora do Estado da Bahia, em Campina Grande, com o nome de Micarande. Desde então, as micaretas ocupam o calendário de várias cidades, como nota-se no Quadro 1.

Quadro 1: Festas ao estilo micaretescos e micaretas de acordo com o mês de realização e classificação das mesmas quanto ao tipo de circuito/espaço utilizado no ano de 2009.

\begin{tabular}{|c|c|c|c|}
\hline $\begin{array}{l}\text { Mês de } \\
\text { realização }\end{array}$ & Nome da Micareta & $\begin{array}{c}\text { Tipo de circuito/ espaço } \\
\text { utilizado }\end{array}$ & Cidade de realização \\
\hline \multirow{3}{*}{ JANEIRO } & Pré-Caju & Out-door & Aracaju/SE \\
\hline & Cabo Folia & In-door & Cabo Frio/RJ \\
\hline & Guarafest & In-door & Guarapari/ES \\
\hline FEVEREIRO & Carnaporto & In-door & Porto Seguro/BA \\
\hline \multirow{4}{*}{ MARÇO } & Axé Brasil & In-door & Belo Horizonte/MG \\
\hline & Micareta da Leiga & In-door & Pelotas/RS \\
\hline & Caldas Fest Folia & In-door & Caldas Novas/GO \\
\hline & Baile da Ressaca & In-door & Colatina/ES \\
\hline \multirow{12}{*}{ ABRIL } & Cuiafolia & In-door & Cuiabá/MT \\
\hline & Folia das Faculdades & In-door & São Paulo/SP \\
\hline & Micareta de Feira & Out-door & Feira de Santana/BA \\
\hline & Jacofolia & Out-door & Jacobina /BA \\
\hline & Ilhéus Praia \& Folia & In-door & Ilhéus/BA \\
\hline & Del Rei Folia & In-door & São João del-Rei/MG \\
\hline & Micarande & Out-door & Campina Grande/PB \\
\hline & Carnabeirão & In-door & Ribeirão Preto/SP \\
\hline & Patosfolia & In-door & Patos de Minas/MG \\
\hline & Sanatório Geral & In-door & Ubá/MG \\
\hline & GV Folia & In-door & Governador Valadares/MG \\
\hline & Rio Preto Fest Folia & In-door & São José do Rio Preto/SP \\
\hline \multirow{4}{*}{ MAIO } & Guia Folia & In-door & São João del-Rei/MG \\
\hline & Carnafacul & In-door & São Paulo/SP \\
\hline & Axé GO Music & In-door & Goiânia/GO \\
\hline & Carnamontes - & In-door & Montes Claros/MG \\
\hline
\end{tabular}

continua... 
conclusão

\begin{tabular}{|c|c|c|c|}
\hline $\begin{array}{l}\text { Mês de } \\
\text { realização }\end{array}$ & Nome da Micareta & $\begin{array}{c}\text { Tipo de circuito/ espaço } \\
\text { utilizado }\end{array}$ & Cidade de realização \\
\hline JUNHO & Colatina Fest Folia & In-door & Colatina/ES \\
\hline \multirow{6}{*}{ JULHO } & Fortal & In-door & Fortaleza/CE \\
\hline & Foliaço & In-door & Ipatinga/MG \\
\hline & Palmas Indoor & In-door & Palmas/TO \\
\hline & Brasilia Indoor & In-door & Brasília/DF \\
\hline & Micarina & In-door & Teresina/PI \\
\hline & Levada Elétrica & In-door & Imperatriz/MA \\
\hline \multirow{5}{*}{ AGOSTO } & Uai Folia & In-door & Belo Horizonte/MG \\
\hline & Carna PA & In-door & Pouso Alegre \\
\hline & Francareta & In-door & Franca/SP \\
\hline & Micarecuia & In-door & Cuiabá/MT \\
\hline & Niterói folia & In-door & Niterói/RJ \\
\hline \multirow{6}{*}{ SETEMBRO } & Micarê Goiânia & In-door & Goiânia/GO \\
\hline & Axé Montes & In-door & Montes Claros/MG \\
\hline & Anapolis Fest Folia & In-door & Anápolis/GO \\
\hline & Axé Folia & In-door & Governador Valadares/MG \\
\hline & Divina Folia & In-door & Divinópolis/MG \\
\hline & Rebola Folia & In-door & Saquarema/RJ \\
\hline \multirow{10}{*}{ OUTUBRO } & VR Folia & In-door & Volta Redonda/RJ \\
\hline & Carnalfenas & In-door & Alfenas/MG \\
\hline & Carna7 & In-door & Sete Lagoas/MG \\
\hline & JF Folia & In-door & Juiz de Fora/MG \\
\hline & Marafolia & Out-door & São Luís/MA \\
\hline & Carnariopreto & In-door & São José do Rio Preto/SP \\
\hline & Axé Uberaba & In-door & Uberaba/MG \\
\hline & TeóFolia & In-door & Teófilo Otoni/MG \\
\hline & Lavras Folia & In-door & Lavras/MG \\
\hline & Baile do Hawaii & In-door & Colatina/ES \\
\hline \multirow{9}{*}{ NOVEMBRO } & Carnavotu & In-door & Votuporanga/SP \\
\hline & Folianópolis & In-door & Florianópolis/SC \\
\hline & Garanheta & In-door & Garanhuns/RS \\
\hline & Sauipefest & In-door & Costa do Sauípe/BA \\
\hline & Rio Axé & In-door & Rio de Janeiro/RJ \\
\hline & Parafolia & In-door & Belém do Pará/PA \\
\hline & Sulfolia & In-door & Rio Grande do Sul \\
\hline & Ribeirão Folia & In-door & Ribeirão Preto/SP \\
\hline & MaceióFest & In-door & Maceió/AL \\
\hline \multirow{2}{*}{ DEZEMBRO } & Carnatal & Out-door & Natal/RN \\
\hline & Revellion Fest Folia & In-door & Caldas Novas/GO \\
\hline \multicolumn{3}{|c|}{ Total de Micaretas } & 63 \\
\hline
\end{tabular}

Fonte: Trabalho de Campo. Valadares (2009). 


\section{Considerações}

Ao analisar as festividades micaretescas atuais e ao discorrer sobre as possíveis origens as quais estão relacionadas, como o Carnaval, percebe-se que houve sensíveis transformações quanto ao propósito inicial de ser uma ruptura no calendário litúrgico e realizada no período da quaresma, significando uma "folga" para os cristãos. Estas festividades, apesar de serem recentes, surgidas com expressão na segunda década do Século XX, e já com aspectos profanos e religiosos diferentes dos apresentados na Europa, não têm mais um recorte temporal restrito à quaresma, transformando-se em festas mercantilizadas e embaladas ao som dos trios elétricos durante praticamente todo ano.

O processo de exportação intensificou a realização das micaretas. Iniciado no final da década de 80 ultrapassou as fronteiras do Estado da Bahia e começou a se espalhar por todo o território nacional. A primeira grande micareta foi a Micarande em 1989, em Campina Grande, na Paraíba, e desde então tantas outras surgiram e marcam o que se convenciona chamar de "carnaval fora de época" em diversos lugares.

A espacialidade da micareta, neste processo temporal de mudanças não ficou restrita somente às ruas, pois locais foram criados e lugares foram ressignificados. $\mathrm{O}$ modelo soteropolitano de micareta, ou seja, aquele baseado no carnaval da cidade de Salvador e exportado para demais locais, tomou posse de espaços públicos e privados, criando um calendário de micaretas que procuram inserir elementos da cultura local, especialmente os "ritmos regionais" que são "eletrificados" nos modelos da música baiana que acompanha os trios.

\section{The MicARETA: HISTORY, CONQUEST AND EXPANSION PACK IN PLACES}

AвstRaCt: This article will explore the history of the parties considered "off season", which were a rupture in the liturgical calendar, as the old sawmill (Portugal) and Micarème (France). In Brazil, the city of Salvador was the scene of the changes in the way of the party. Modifications and direct interference of the city Salvador changed the configuration of the party and this began to be "exported" and there is currently micaretesco a circuit that extends throughout the year. The micaretas won their own places, exceeded the initial connection time and redefined the model of party, with the new face tied to the electric trios Carnival of Salvador.

Keywords: Micareta, Carnival out of Season, "Salvador-BA (Brazil).” 


\section{REFERÊNCIAS}

ALENCAR, Hélder. 31 anos de Micareta (de feira de Santana). Feira de Santana: [s.ed.], 1968.

ARAÚJO, Rita de Cássia Barbosa de. Mi-Caréme: um outro carnaval. Na série Folclore, n. 269. Centro de Estudos Folclóricos, do Instituto de Pesquisas Sociais, da Fundação Joaquim Nabuco, 2000.

BAKHTIN, Mikhail. A cultura popular na Idade Média e no Renascimento: o contexto de François Rabelais. São Paulo: Hucitec, 1987.

BRAGA, Teófilo. O povo português nos seus costumes, crenças e tradições. Lisboa: Publicações Dom Quixote, 1985. V. 2.

BRANDÃO, Carlos Rodrigues. A cultura na rua. Campinas. São Paulo: Papirus, 1989.

CASCUDO, Luís da Câmara. Dicionário do folclore brasileiro. São Paulo: Melhoramentos; Brasília: Instituto Nacional do Livro, 1979.

DEL PRIORE, M. A serração da velha: charivari, morte e festa no mundo lusobrasileiro. In: JANCSÓ, I., KANTO, I. (Orgs.). Cultura e sociabilidade na América portuguesa. São Paulo: Fapesp, 2001, v. I, p. 279 - 300.

DUARTE, José Carlos Silveira. De mídia e festa, a micareta. 2005. 171p. Dissertação (Mestrado em Comunicação e Cultura Contemporâneas) - Universidade Federal da Bahia, Salvador, 2005.

ENCICLOPÉDIA Delta Larousse, Rio de Janeiro: Delta, 1992. $20 \mathrm{v}$.

FERREIRA, Felipe. O Livro de ouro do carnaval brasileiro. Rio de Janeiro: Ediouro, 2004.

JORNAL A Ribalta. Mi-careme. Jornal A Ribalta, Vitória da Conquista, 12 abril. 1927. 6. ed. p. 10.

JORNAL O Libador. Folia Jacobinense. Jornal O Libador, Jacobina, 7 abril. 1935, p. 7.

LEMOS, Doracy Araújo. Jacobina, sua história e sua gente/memórias, Jacobina. D. A. Lemos, 1995.

MORAES, Eneida. História do carnaval carioca. Rio de Janeiro: Civilização Brasileira, 1958.

NICÉIAS, Alcides. Verbetes para uma história do carnaval brasileiro. Sorocaba, 1991. POHL, J. E. Viagem ao interior do Brasil. Belo Horizonte: Itatiaia, 1976.

REGO, Valdeloir. Capoeira Angola: ensaio sócio-etnográfico. Salvador: Itapuã, 1968.

SANTOS, Vanicléia Silva. Sons, danças e ritmos: A Micareta em Jacobina-Ba (19201950), Dissertação (Mestrado em História) - Pontifícia Universidade Católica, São Paulo, 2001. 
SILVA, Alcira Pereira Carvalho. Jacobina Sim. Bahia: Ed. da UFBA, 1986.

SILVA, Tagore Trajano de Almeida. Apropriação dos Espaços Públicos Durante o Carnaval de Salvador/Bahia/Brasil: sintese das desigualdades sociais. Disponível em: <http://www.conpedi.org/manaus/arquivos/anais/salvador/tagore_trajano. pdf $>$. Acesso em: [- - .

THOMPSON, Edward P. Costumes em comum. São Paulo: Cia. das Letras, 1998.

VAINSENCHER, Semira Adler. Serração da Velha. In: Pesquisas Centro de Estudos Folclóricos, do Instituto de Pesquisas Sociais, da Fundação Joaquim Nabuco, 21 de janeiro de 2008. Disponível em: <http://www.fundaj.gov.br/notitia/servlet/newstorm. ns.presentation. NavigationServlet?publicationCode $=16 \&$ pageCode $=317 \&$ textCod $\mathrm{e}=10222 \&$ date $=$ currentDate $>$.

VIANNA, Antônio. Casos e coisas da Bahia. Salvador: Fundação Cultural do Estado da Bahia, 1986.

VIANNA, Hildegardes. Calendário das festas populares da cidade do Salvador, Salvador: Prefeitura Municipal de Salvador, 1983. 